after injection of $22 \mu \mathrm{gm}$. per gram of animals, only nogligible amounts could be recovered. Here, too, none was found in the excreta. One of us (F.J. O.) deals with this subject in the following communication.

As to the nature of the metabolites of gamma-BHC we are entirely ignorant. It should be emphasized that breakdown in the above sense and detoxication (conversion into a non-toxic compound) noed not parallel each other.

Investigations concerning the metabolism of other isomers of BHC are in progress now. Moroover, a closer study of the correlations between the symptoms of intoxication and the course of the metabolic changes after administration of different isomers of $\mathrm{BHC}$ is to bo made.

K. van Asperen

F. J. OPPENOORTH

Laboratory for Research on Biocidos, National Council for Agricultural Research T.N.O.,

Vondellaan 6, Utrecht. Jan. 14.

'Asperen, K. van, and Oppenoorth, F. J., Chemisch Weekblad (in the press, 1954) (Dutch text only; publication in English will follow in due coursc).

- Rolth, J. F., Chemisch Weekblad, 49, 691 (1953) (Dutch text only).

- Schechter, M. S., and Fornstein, I., A nal. Chem., 24, 544 (1052).

\title{
Metabolism of Gamma-Benzene Hexachloride in Susceptible and Resistant Houseflies
}

THE metabolism of gamma-BHC was studied in three strains of houseflies : a susceptible strain $(S)$ and two gamma.BHC-resistant strains $\left(R_{1}, R_{2}\right)$, one of which was also resistant to DD' $\left(R_{2}\right)$. The method used was as described in the preceding communication.

The flies were injected into the thorax with $0 \cdot 3 \mu \mathrm{gm}$. gamma-BHC in $0.3 \mathrm{~mm}^{\mathrm{a}}$ of an emulsion of peanut oil. Groups of seventy flies, thus receiving $22 \mu \mathrm{gm}$. ., were kept at $25^{\circ} \mathrm{C}$. for varying periods of time, after which the amount of gamma-BHC was estimated. As no gamma-BHC was found in the excreta, a decresse of the amount of the toxicant in the flies indicates that it is metabolized.

It is shown in Fig. I that a rapid breakdown occurs in the resistant strains, and that the susceptible strain is also able to metebolize the poison. In the latter the process is slower at the beginning and eventually it ceases completely. This can perhaps be explained by the fact that in these flies heavy symptoms build up soon after injeotion, followed by death after a fow hours.

In a number of experiments the abdomens were cut off thirty minutes after injection. It could be 


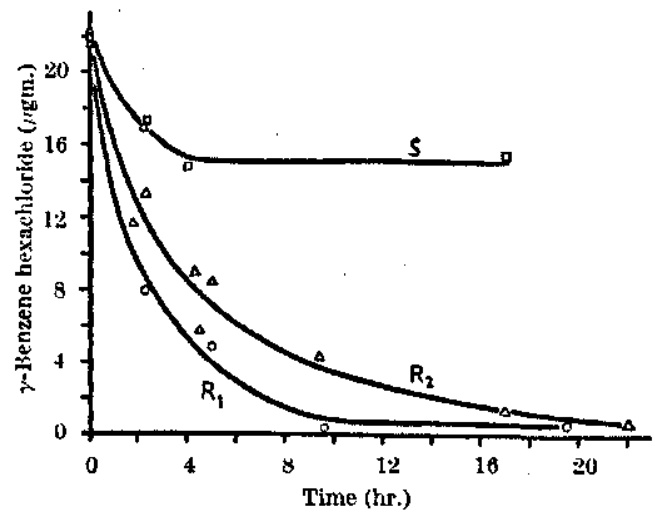

Fig. 1. Amount of $\gamma$-BHC in seventy flies plotted againgt time after injection, $S$, susceptible strain, dying after a few hours; $\boldsymbol{R}_{\mathrm{t}}, \gamma$-BHC-resistant strain; $\boldsymbol{R}_{\mathrm{t}}, \boldsymbol{\gamma}$-BHC- and DDW-resistant strain

shown that the breakdown is going on for at least fow hours in both parts of the body. It follows that neither the Malpighian tubes nor the fat body can be the only site of the breakdown. Thirty minutes after injection the abdomens, which represent only 25 per cent of the body-weight, contrained more than half the poison present. As they contain 75 per cent of the body.fat, it is likely that storage in the fat depots occurs, which also seems to play a part in mice (see preceding communication).

A rapid breakdown in susceptible flies may perhaps also be inferred from the data of Bradbury et al. ${ }^{2}$. Using radioactive gamma-BHC they found an uptake of $34 \mu \mathrm{gm}$. per gram of flies in four hours, an amount which would rapidly have killed their flies if no detoxication had occurred. It should be stressed that the metabolism found in our experiments need not parallel a detoxication process.

The question whether a difference in breakdown between susceptible and resistant strains is the cause of their difference in susceptibility remains to be settled. A comparison between the two strains, of course, should be made at concentrations at which both will survive. Work on this subject is in progress in our Laboratory.

\section{F. J. OppenOoRTH}

Laboratory for Research on Biocides, National Council for Agricultural Research T.N.O., Vondellaan 6, Utrecht.

'Bradbury, F. R., Nield, P., and Newman, J. F., Nature, 172, 1052 (1953). 